\title{
Single-cell measurement of ammonium and bicarbonate uptake within a photosymbiotic bioeroding sponge
}

\author{
Michelle Achlatis $\mathbb{1}^{1,2,3} \cdot$ Mathieu Pernice $\mathbb{1}^{4} \cdot$ Kathryn Green ${ }^{5} \cdot$ Paul Guagliardo ${ }^{6} \cdot$ Matthew R Kilburn $\mathbb{1}^{6}$. \\ Ove Hoegh-Guldberg ${ }^{1,2,3} \cdot$ Sophie Dove ${ }^{1,2}$
}

Received: 26 September 2017 / Accepted: 12 December 2017 / Published online: 31 January 2018

(c) International Society for Microbial Ecology 2018

\begin{abstract}
Some of the most aggressive coral-excavating sponges host intracellular dinoflagellates from the genus Symbiodinium, which are hypothesized to provide the sponges with autotrophic energy that powers bioerosion. Investigations of the contribution of Symbiodinium to host metabolism and particularly inorganic nutrient recycling are complicated, however, by the presence of alternative prokaryotic candidates for this role. Here, novel methods are used to study nutrient assimilation and transfer within and between the outer-layer cells of the Indopacific bioeroding sponge Cliona orientalis. Combining stable isotope labelling, transmission electron microscopy (TEM) and nanoscale secondary ion mass spectrometry (NanoSIMS), we visualize and measure metabolic activity at the individual cell level, tracking the fate of ${ }^{15} \mathrm{~N}$-ammonium and ${ }^{13} \mathrm{C}$-bicarbonate within the intact holobiont. We found strong uptake of both inorganic sources (especially ${ }^{13}$ C-bicarbonate) by Symbiodinium cells. Labelled organic nutrients were translocated from Symbiodinium to the Symbiodinium-hosting sponge cells within $6 \mathrm{~h}$, and occasionally to other sponge cells within 3 days. By contrast, prokaryotic symbionts were not observed to participate in inorganic nutrient assimilation in the outer layers of the sponge. Our findings strongly support the metabolic interaction between the sponge and dinoflagellates, shedding light on the ecological advantages and adaptive capacity of photosymbiotic bioeroding sponges in oligotrophic marine habitats.
\end{abstract}

Electronic supplementary material The online version of this article (https://doi.org/10.1038/s41396-017-0044-2) contains supplementary material, which is available to authorized users.

Michelle Achlatis

m.achlatis@uq.edu.au

$\triangle$ Mathieu Pernice

mathieu.pernice@uts.edu.au

1 School of Biological Sciences, Coral Reef Ecosystems Laboratory, The University of Queensland, St. Lucia, QLD 4072, Australia

2 Australian Research Council Centre of Excellence for Coral Reef Studies, The University of Queensland, St. Lucia, QLD 4072, Australia

3 Global Change Institute, The University of Queensland, St. Lucia, QLD 4072, Australia

4 Climate Change Cluster, University of Technology Sydney, Ultimo, NSW 2007, Australia

5 Centre for Microscopy and Microanalysis, The University of Queensland, Brisbane, QLD 4072, Australia

6 Centre for Microscopy, Characterisation and Analysis, The University of Western Australia, Perth, WA 6009, Australia

\section{Introduction}

Coral reefs are among the most productive and biodiverse ecosystems, and are the result of a fragile balance between accretion of calcium carbonate by calcifying organisms, and its loss by physical, chemical or biological erosion (bioerosion). At the heart of reef accretion is the mutualistic symbiosis between scleractinian corals and dinoflagellates of the genus Symbiodinium [1, 2]. Interestingly, Symbiodinium have also been linked to the opposite side of the carbonate balance, potentially powering the activities of a prominent group of bioeroding sponges from the genus Cliona [3-6].

Bioeroding sponges contribute substantially to the excavation of coral skeletons, accounting often for $40-70 \%$ and up to $>90 \%$ of macroborer activity on coral reefs [7]. They chemically etch and mechanically remove calcium carbonate $\left(\mathrm{CaCO}_{3}\right)$ chips from the skeletons of organisms such as corals $[8,9]$, adopting an endolithic lifestyle that often results in the death of the calcareous host $[10,11]$. The photosymbiotic Cliona viridis species complex consists of competitive and fast-spreading bioeroding sponges that host 
intracellular Symbiodinium in archaeocyte-like cells of the sponge pinacoderm (or outer layer) where light levels are highest $[12,14]$. This symbiosis is hypothesized to explain observations of enhanced growth and bioerosion rates in the light [3-5, 15]. Besides Symbiodinium, photosymbiotic clionaids belong to the 'low microbial abundance' sponges, harbouring sparse prokaryotic communities in their mesohyl, typically to a similar concentration as in the surrounding seawater [15, 16]. 'High microbial abundance' sponges on the contrary can host communities that are 2-4 orders of magnitude more concentrated [17]. In addition, these clionaid prokaryotic communities are perhaps phylogenetically less diverse in comparison to those of other sponge holobionts (ie, the collective community of the host and its microbial symbionts) $[16,18]$.

The presence of a small prokaryotic community complicates definitive attribution of metabolic involvement by Symbiodinium in host performance, despite evidence that seawater spiked with $\mathrm{NaH}^{13} \mathrm{CO}_{3}$ leads to initial ${ }^{13} \mathrm{C}$ enrichment of the pinacoderm of Cliona varians followed by translocation to the choanosome (or inner layer that contains sponge choanocytes) [6]. The complication is driven by the observations that: (1) the marine sponge literature strongly supports a metabolic role for intracellular (or intercellular) prokaryotic communities in the fixation of inorganic carbon and transfer of glycerol or small organic phosphates for host growth and reproductive capacity [16, 19, 20], and, (2) it appears that it is microbial identity, not quantity, that determines the quantity of organic carbon translocated to sponge hosts with some photoautotrophic cyanobacteria found not to translocate fixed products to their host [21-23].

Attributing assimilation of inorganic nitrogen to Symbiodinium within a clionaid holobiont is likewise complicated by multiple potential candidates for this role. Freshly isolated Symbiodinium avail themselves of inorganic and organic forms of nitrogen [24], and within a coral host Symbiodinium acquire ammonium (mainly through the glutamine synthetase/glutamate synthase (GS/GOGAT) pathway [25]) or nitrate from the seawater surrounding their host [26]. Prokaryotic symbionts, however, are also associated with moderating nitrogen availability within sponges [27, 28]. For example, some assimilate ammonium into glutamate via the GS/GOGAT pathway, and this assimilation proceeds irrespective of the presence of autotrophic-eukaryotic symbionts such as diatoms [29-31]. At the same time, the enzyme glutamate dehydrogenase (GDH) provides an alternate pathway for converting ammonium into amino acids, leading to the conclusion that a range of invertebrate phyla also have the capacity to directly assimilate inorganic nitrogen [32-35]. In Porifera, genomic domains of GDH and GS are putative [36], with evidence of GS expression in a clionaid sponge [37]. While to date there is no evidence for a GOGAT enzyme in sponge genomes (Supplementary Table S1), it is nonetheless possible that sponge cells, that are not evolutionarily far removed from a Protist origin [38], can directly assimilate ammonium via GDH.

While a metatranscriptomic analysis in the diatom harbouring sponge Cymbastela concentrica revealed the functional potential of the diatoms in terms of carbon (fixed through photosynthesis) and nitrogen (assimilated or produced) contributed to other members of the holobiont [31], similar studies are lacking in bioeroding sponges. Here, we use the prominent Indopacific bioeroding sponge Cliona orientalis as a model system to examine the realized rather than potential metabolic contributions of the host and symbiont community to holobiont energetics, and to assess the ability of such sponges to directly assimilate inorganic carbon (as bicarbonate) and nitrogen (as ammonium). Following a pulse-chase experiment, we capitalized on the integration of isotopic labelling, transmission electron microscopy (TEM) and nanoscale secondary ion mass spectrometry (NanoSIMS) to detect in situ metabolic activity at the subcellular level while targeting cell types of interest (eg, [26, 35, 39, 40]). We quantitatively and qualitatively mapped the uptake, assimilation and distribution of the isotopically labelled materials over time at the singlecell level of the outer sponge layer, exploring whether the dinoflagellates form the primary site of inorganic assimilation into organic material, and whether this assimilated material is subsequently translocated to sponge cells.

\section{Materials and Methods}

\section{Collection and maintenance of sponges}

C. orientalis sponges in encrusting 'beta' morphology [41] were collected at $5 \mathrm{~m}$ depth at Tenements $2\left(151.9302^{\circ} \mathrm{E}\right.$, $\left.23.4326^{\circ} \mathrm{S}\right)$, Heron Reef slope, Great Barrier Reef in February 2016 (Fig. 1a-d). To standardize the specimen size, cylindrical cores of $35 \mathrm{~mm}$ in diameter were extracted using a circular pneumatic drill from seven different individuals (Fig. 1b). The species identity was confirmed upon examination of the sponge spicules under the light microscope [11] (Fig. 1c). The sponge cores were transferred to the outdoor flow-through seawater system at the Heron Island Research Station for 2 weeks of healing, and were then randomly distributed to three experimental aquaria (40 L each) and acclimated for 10 days. The aquaria and lids were covered with Marine Blue 131 light filters (Lee Filters, Andover, UK) to mimic the typical light spectrum of the collection depth [42]. Over the duration of the experiment noon irradiance was $520 \pm 73 \mu \mathrm{mol}$ quanta per $\mathrm{m}^{2}$ per $\mathrm{s}$ and noon temperature was 


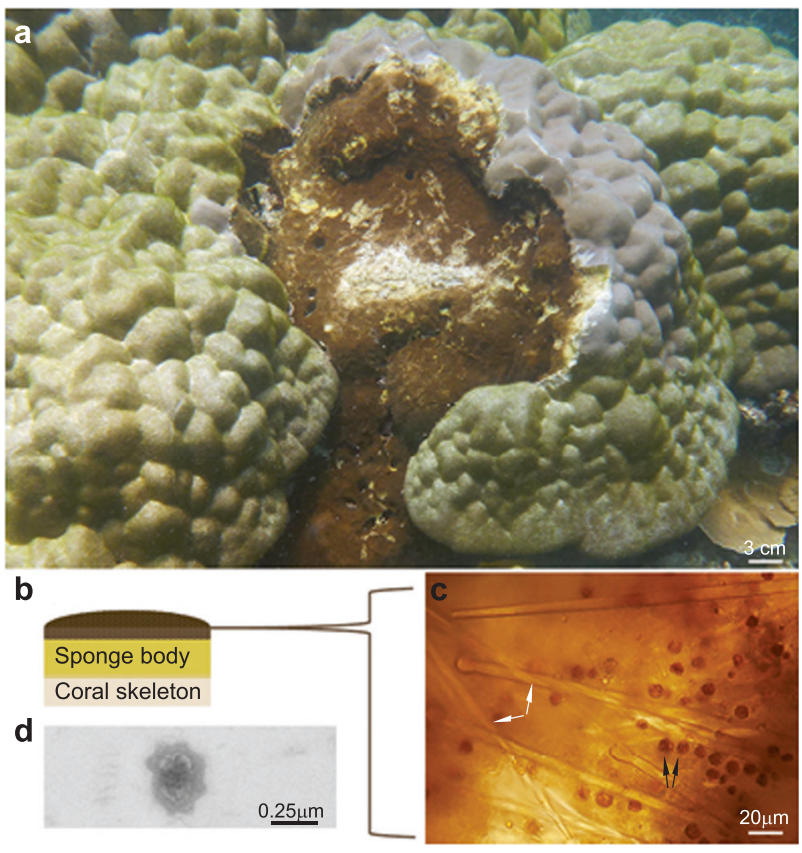

Fig. 1 The photosymbiotic bioeroding sponge Cliona orientalis from the Great Barrier Reef, Australia. a $C$. orientalis(brown patch), here eroding a massive Porites lobata colony on Heron Reef, is the most abundant and aggressive representative of the $C$. viridis species complex on the Great Barrier Reef [76]. Such sponges can reach several square metres in surface area at over $1 \mathrm{~cm}$ of substrate penetration and they habitually attack and kill live corals. They not only etch the coral skeleton endolithically but they also compete with coral polyps, attacking from beneath where defensive nematocysts are absent and expanding laterally over the coral colony thereby increasing their light-harvesting surface. b Diagram depicting a cross section of experimental cores ( $35 \mathrm{~mm}$ in diameter) extracted out of the sponge using a circular drill, revealing the different functional layers. The outer sponge layer (brown, investigated in the current study) hosts dinoflagellates of the genus Symbiodinium, while the underlying layer where light does not reach consists of sponge material without dinoflagellates (ochre yellow, not investigated here) and is rich in aquiferous canals that circulate water through the body for, eg, respiration and heterotrophy. Both layers are rock-hard because the sponge biomass is finely intertwined inside the $\mathrm{CaCO}_{3}$ substrate. The lowest layer (beige) consists of coral skeleton that is not yet infested by the sponge. c The dinoflagellate-rich sponge layer (pinacoderm, black arrows point at individual dinoflagellates $)$ as seen under the light microscope $(\times 400$ magnification). The sponge also secretes its own inorganic skeleton made of siliceous spicules (tylostyles, white arrows). d TEM image of an unidentified bacterium sparsely found in the mesohyl of the outer layer of $C$. orientalis. Other than Symbiodinium, the sponge hosts a low abundance of microbes (like C. varians, [16]) such as Alpha- and Gammaproteobacteria [79]

$27.2 \pm 0.3{ }^{\circ} \mathrm{C}$ in the experimental tanks (mean $\pm \mathrm{SD}$ measured by Odyssey and HOBO Pendant loggers).

\section{Pulse-chase labelling experiment}

To examine the assimilation of inorganic nitrogen and carbon within the holobiont, sponge cores were exposed to a labelling treatment with isotopically enriched artificial seawater (Supplementary Figure S1). The seawater contained enriched ammonium chloride powder $\left({ }^{15} \mathrm{NH}_{4} \mathrm{Cl},{ }^{15} \mathrm{~N}\right.$ isotopic abundance of $98 \%$ ) and enriched sodium bicarbonate powder $\left(\mathrm{NaH}^{13} \mathrm{CO}_{3},{ }^{13} \mathrm{C}\right.$ isotopic abundance of $99 \%$ ) to a final concentration of $5 \mu \mathrm{M}$ and $2 \mathrm{mM}$, respectively. The ${ }^{15} \mathrm{NH}_{4} \mathrm{Cl}$ concentration was based on ecological (summer concentrations of 0.9-9.1 $\mu \mathrm{M} \mathrm{NH}_{4}{ }^{+}$at the Heron reef slope [43] and $\mathrm{NH}_{4}{ }^{+}$-rich pulses frequently contributed by reef fish [44]) and methodological relevance (same concentration used by [45]). Both powders were supplied by Sigma Castle Hill, NSW, Australia and the enriched treatment was prepared according to Pernice et al. [45]. The sponge cores were incubated over a $6 \mathrm{~h}$ pulse (starting at 06:30 hours) in three independent closed-water chambers filled to $3 \mathrm{~L}$ and equipped with a small wave maker. Each chamber was partially submerged into the $40 \mathrm{~L}$ aquaria, which served as water baths for temperature regulation, and was covered by the aquarium lid. After the pulse phase $(0-6 \mathrm{~h})$, labelled cores were moved back to the natural flow-through seawater of the $40 \mathrm{~L}$ aquaria (without exposing them to air) for the chase phase (6-72 h). Sponge replicates were randomly sampled at $t=0,6$ and 72 $\mathrm{h}$, respectively. Background enrichment levels were determined at $t=0 \mathrm{~h}$ from sponges in non-enriched artificial seawater containing ${ }^{14} \mathrm{NH}_{4} \mathrm{Cl}$ and $\mathrm{NaH}^{12} \mathrm{CO}_{3}$ powder to the same concentration as the labelling treatment. Sampled sponge cores were vertically halved, the first half being snapfrozen and stored at $-80^{\circ} \mathrm{C}$ for Symbiodinium extractions, and Symbiodinium-rich sponge material from the upper surface of the second half being fixed for further TEM and NanoSIMS analysis.

\section{Sample fixation and TEM analysis}

$\mathrm{CaCO}_{3}$ from the coral substrate was carefully removed to isolate intact sponge material, remove non-assimilated inorganics and embed the samples for TEM (details in Supplementary text S1). Sponges were cut into $120 \mathrm{~nm}$ sections using an Ultracut UC6 microtome (Leica Microsystems, Australia). Selected sections were stained with uranyl acetate and lead citrate on finder grids (Electron Microscopy Sciences, Hatfield, PA, USA) and viewed at 80 $\mathrm{kV}$ accelerating voltage using a JEOL 1011 Transmission Electron Microscope at the Centre for Microscopy and Microanalysis (University of Queensland, Brisbane). Sponge regions $(\sim 35 \times 35 \mu \mathrm{m})$ of high-embedment quality that contained cellular structures of interest (I, II and III defined below) were identified and marked on a separate digital map of the grid so that they could be located by the instrument camera during the NanoSIMS analysis.

\section{NanoSIMS analysis}

In order to examine the ${ }^{15} \mathrm{~N}$ and ${ }^{13} \mathrm{C}$ organic enrichment in the sponge holobiont over time and space, the selected 


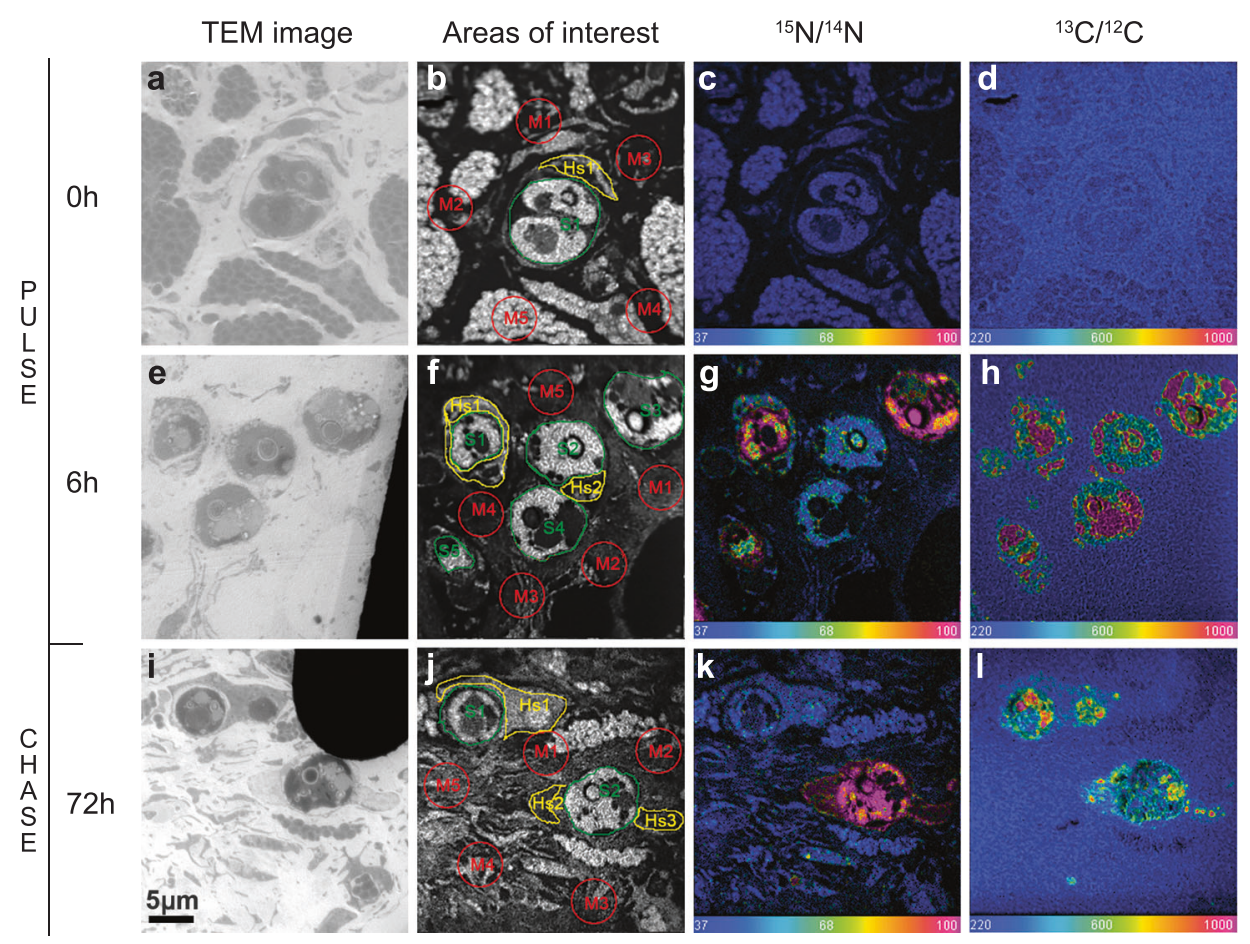

Fig. 2 Visualization of ${ }^{15} \mathrm{~N}$-ammonium and ${ }^{13} \mathrm{C}$-bicarbonate assimilation in the photosymbiotic bioeroding sponge holobiont Cliona orientalis, with a focus on the resident dinoflagellates of the genus Symbiodinium. a, e, i TEM images of three selected holobiont samples before the addition of label $(t=0 \mathrm{~h})$, at the end of the pulse period $(t=$ $6 \mathrm{~h})$ and at the end of the chase period $(t=72 \mathrm{~h}) . \mathbf{b}, \mathbf{f}, \mathbf{j}$ NanoSIMS ${ }^{12} \mathrm{C}^{14} \mathrm{~N}^{-}$image displaying the selection of the areas of interest (AOI) for enrichment quantification: (I) Symbiodinium (in green, S, total measured $n=113$ ), (II) Cytoplasm of Symbiodinium-hosting sponge cells (in yellow, Hs, $n=82$ ) and (III) nearby mesohyl cells and intercellular space (in red, M, $n=150$ ) (see also Fig. 3a). c, g, k Distribution of ${ }^{15} \mathrm{~N} /{ }^{14} \mathrm{~N}$ ratio and $\mathbf{d}, \mathbf{h}, \mathbf{l}$ of ${ }^{13} \mathrm{C} /{ }^{12} \mathrm{C}$ ratio over the same

regions of the same sections were imaged with a NanoSIMS ion probe (NanoSIMS 50, CAMECA, Paris, France) at the Centre for Microscopy, Characterisation, and Analysis (University of Western Australia, Perth) using methodology previously established in Cnidaria (Supplementary text S1) [35, 45, 46]. Analysis of the NanoSIMS results (Fig. 2) focused on three areas of interest (AOI) all within the outer sponge layer, namely (I) Symbiodinium cells (typical diameter $7-10 \mu \mathrm{m}$ ), (II) surrounding cytoplasm of the host archaeocyte-like cells that contain Symbiodinium (selections of approximately $5 \mu \mathrm{m}$ in diameter), hereafter termed Symbiodinium-hosting cells, and (III) random selections of unidentified sponge or microbial cells and intercellular space of the mesohyl matrix in the same field of view as the Symbiodinium cells (diameter $5 \mu \mathrm{m}$ ) (Figs. $2 \mathrm{~b}, \mathrm{f}, \mathrm{j}$ and $3 \mathrm{a}$ ). Symbiodinium-hosting cells were not observed to host other microorganisms, which were overall sparse in the examined sponge layer. In total, we analysed 5 individual sponges, with on average 6 raster regions containing 70 AOI per sponge (see Supplementary Table S2 for details). selected areas as obtained through NanoSIMS analysis at each of the three time points. The images show the deviation of the ratios from the natural abundance ratio, using a rainbow scale in hue saturation intensity. The rainbow scale ranges from natural abundance in blue (0.0037 for ${ }^{15} \mathrm{~N} /{ }^{14} \mathrm{~N}$ and $2 \times 0.0110$ for ${ }^{13} \mathrm{C} /{ }^{12} \mathrm{C}$ ) to several-fold enrichment above natural abundance in red (approximately threefold for ${ }^{15} \mathrm{~N} /{ }^{14} \mathrm{~N}$ and 5 -fold for ${ }^{13} \mathrm{C} /{ }^{12} \mathrm{C}$ ). Heterogeneity in label incorporation is exemplified by $\mathbf{k}$ and $\mathbf{l}$, where Symbiodiniumcell $\mathrm{S} 1$ that was measured simultaneously to Symbiodinium cell S2 shows disproportionately low nitrogen uptake in comparison to carbon. Individual isotopic ratios per AOI are given in the Supplementary Table S2

Consulting the corresponding TEM images, all AOI were drawn onto the ${ }^{12} \mathrm{C}^{14} \mathrm{~N}^{-}$maps, which do not display the enrichment levels for an unbiased selection. Once the ${ }^{15} \mathrm{~N} /{ }^{14} \mathrm{~N}$ and ${ }^{13} \mathrm{C} /{ }^{12} \mathrm{C}$ ratio maps were obtained (Fig. 2c, g, k, $\mathrm{d}, \mathrm{h}, \mathrm{l}$ ), the AOI were superimposed on the NanoSIMS maps allowing extraction and quantification of the mean ${ }^{15} \mathrm{~N} /{ }^{14} \mathrm{~N}$ and ${ }^{13} \mathrm{C} /{ }^{12} \mathrm{C}$ ratios of the selected cells. Enrichments levels were expressed using delta notations $\left(\delta^{15} \mathrm{~N}\right.$ and $\delta^{13} \mathrm{C}$ in \%o) as follows:

$$
\begin{aligned}
& \delta^{15} \mathrm{~N}=\left(\frac{N_{\mathrm{mes}}}{N_{\mathrm{nat}}}-1\right) \times 10^{3}, \\
& \delta^{13} \mathrm{C}=\left(\frac{C_{\mathrm{mes}}}{C_{\mathrm{nat}}}-1\right) \times 10^{3},
\end{aligned}
$$

where $N_{\text {mes }}$ is the ${ }^{15} \mathrm{~N} /{ }^{14} \mathrm{~N}$ ratio measured in labelled sponges and $N_{\text {nat }}$ is the natural ${ }^{15} \mathrm{~N} /{ }^{14} \mathrm{~N}$ ratio measured in AOI of non-labelled control sponge samples. Similarly, $C_{\text {mes }}$ is the ${ }^{13} \mathrm{C} /{ }^{12} \mathrm{C}$ ratio measured in the AOI of the labelled sponges and $C_{\text {nat }}$ is the natural ${ }^{13} \mathrm{C} /{ }^{12} \mathrm{C}$ ratio. Using the same 


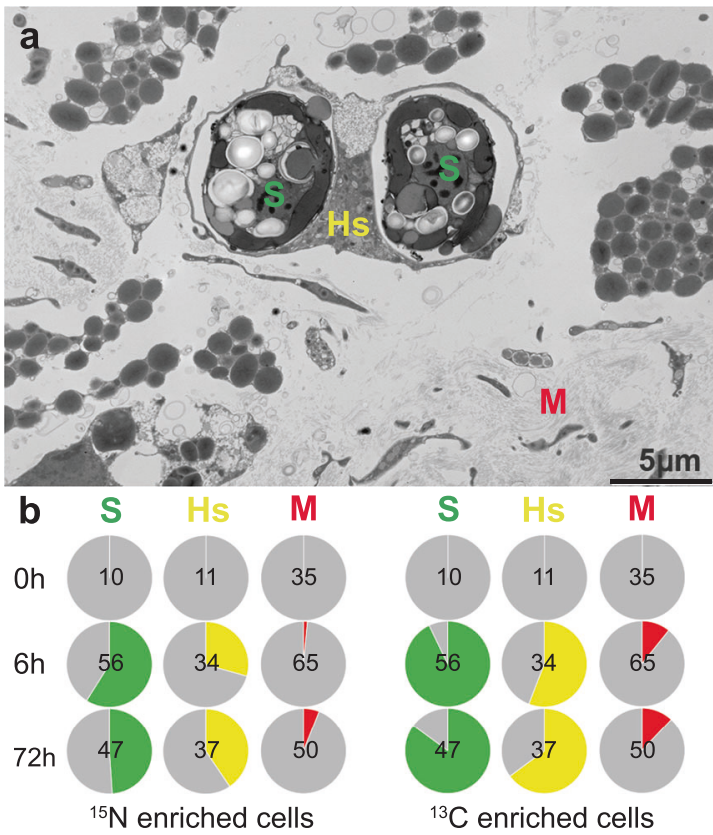

Fig. 3 Distribution of ${ }^{15} \mathrm{~N}$ - and ${ }^{13} \mathrm{C}$-enriched and non-enriched cells of three cellular structures of interest in the bioeroding sponge holobiont Cliona orientalis, with a focus on its resident dinoflagellates of the genus Symbiodinium. a TEM displaying examples of the cellular areas of interest (AOI) examined: (I) Symbiodinium (in green, S), (II) Symbiodinium-hosting sponge cells (in yellow, Hs) and (III) nearby mesohyl cells and intercellular material (in red, M). b Pie charts illustrating the distribution of ${ }^{15} \mathrm{~N}$ - and ${ }^{13} \mathrm{C}$-enriched and non-enriched cells for each of the AOI displayed in a as obtained from NanoSIMS quantification. The numbers on the pie charts correspond to the AOI replicates $(n=\ldots)$ analysed at each time point

NanoSIMS methodology and resolution, enriched prokaryotic cells have been detected in the $C$. orientalis choanosome after a pulse of organic compounds (Achlatis et al., unpublished data), demonstrating the capacity of the current methodology to detect enrichment of cells that are $>10$-fold smaller than Symbiodinium. After the enrichment levels were determined, enriched versus non-enriched AOI were distinguished for each time point and their proportions as fractions of the measured AOI population were determined. Only the enriched AOI were considered when calculating mean enrichment levels.

\section{Symbiodinium-specific ${ }^{15} \mathrm{~N}$-ammonium and ${ }^{13} \mathrm{C}$ - bicarbonate uptake rates}

Since uptake by Symbiodinium was found to be dominant (Results), the sponge material of the remaining halves of the cores was used to determine the surface areas of the sponge, the Symbiodinium population density and the nitrogen and carbon content of the Symbiodinium fraction as detailed in the Supplementary text S1. These parameters were then used to determine the ammonium and bicarbonate assimilatory capacity of the dinoflagellate symbionts.

\section{Statistical analysis}

Statistical analyses were done in Primer v6 [47] with permutational analysis of variance (PERMANOVA) add-on. Permutational analysis of variance is a semiparametric test that offers both the flexibility of distribution-free tests and the partitioning to analyse complex designs while considering interaction terms [48]. While typically used in multivariate approaches, it provides useful tools for univariate data sets [48] generated by low-throughput methods, such as NanoSIMS [39, 49]. The pseudo- $F$ statistic was derived from dissimilarity matrices constructed with Euclidean distance and the $P_{(\text {perm })}$ value was based on 4999 permutations under a full model using type III sums of squares to account for the unbalanced design. A two-factor design with Treatment (pre-pulse $t=0 \mathrm{~h}$, post-pulse $t=6 \mathrm{~h}$ and post-chase $t=72 \mathrm{~h}$ ) and AOI ((I), (II), (III)) was used to test for differences in ${ }^{15} \mathrm{~N}$ or ${ }^{13} \mathrm{C}$-enrichment levels of each AOI over time, and between the AOI of each time point. Pairwise post hoc comparisons were conducted using permutational pseudo- $t$ tests when significant factor effects were found. Detailed statistical outputs are given in Supplementary Table S3. For each AOI type, two-proportion $z$ tests [50] computed in Statistica v13 (Dell, California, USA) were used to compare (a) the proportion of enriched AOI at $t=6 \mathrm{~h}$ to the proportion enriched at $t=72 \mathrm{~h}$ for both nitrogen and carbon and (b) the proportion of ${ }^{15} \mathrm{~N}$-enriched cells to that ${ }^{13} \mathrm{C}$-enriched cells and both $t=6 \mathrm{~h}$ and $t=72 \mathrm{~h}$ (Supplementary Table S4). Throughout the paper, results are considered significant at the $p<0.05$ level.

\section{Results and Discussion}

\section{Single-cell enrichments through NanoSIMS analysis}

The NanoSIMS analysis detected nitrogen and carbon enrichment in the sponge and/or symbiont cells on thin surface planes, allowing for visualization of the enrichment levels in the intact holobiont (Fig. 2). The enrichment images were compared to the TEM images of the same sponge areas and therefore the corresponding cell structures were accurately identified (Fig. 2a, e, i). The isotopic ratios $\left({ }^{15} \mathrm{~N} /{ }^{14} \mathrm{~N}\right.$ and $\left.{ }^{13} \mathrm{C} /{ }^{12} \mathrm{C}\right)$ were separately measured and compared to natural abundance ratios of unlabelled control samples for each area of interest (AOI, Fig. 3a; individual values in Supplementary Table S2).

The nitrogen enrichment levels of the examined AOI differed between the treatment time points (pseudo-F = 4.483, $P_{(\text {perm })}=0.032$ ). Dinoflagellate cells present in the outer layer of the sponge displayed a substantial ${ }^{15} \mathrm{~N}$ enrichment of $1416 \pm 360 \%$ o (mean \pm SEM) after the $6 \mathrm{~h}$ pulse of enriched seawater (pairwise comparison between 

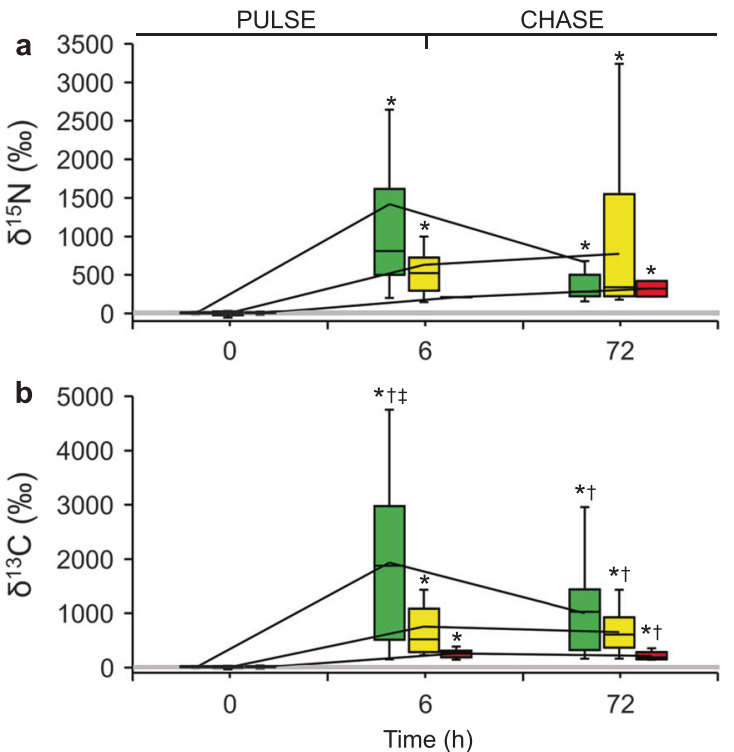

$\square$ Symbiodinium $\square$ Host cell cont. Symbiodinium $\square$ Mesohyl

Fig. 4 Quantification of a nitrogen and $\mathbf{b}$ carbon assimilation in enriched host and symbiont cells of the bioeroding sponge Cliona orientalis in response to a pulse of seawater enriched in ${ }^{15} \mathrm{~N}$ ammonium and ${ }^{13} \mathrm{C}$-bicarbonate. Through NanoSIMS isotopic analysis, the mean ${ }^{15} \mathrm{~N}$ and ${ }^{13} \mathrm{C}$ enrichments were quantified in three areas of interest (AOI): (I) Symbiodinium (in green), (II) cytoplasm of Symbiodinium-hosting sponge cells (in yellow) and (III) nearby mesohyl cells and intercellular space (in red). Individual values are given in Supplementary Table S2. Significant differences $\left(P_{(\text {perm })}<0.05\right)$ are marked between $t=0 \mathrm{~h}$ and enriched samples $(*)$, between enriched samples from $t=6 \mathrm{~h}$ to $t=72 \mathrm{~h}\left({ }^{\ddagger}\right)$ and between different AOI within the same time point $\left({ }^{\dagger}\right)$ (Supplementary Table S3). The grey lines and their width depict the range of the natural ${ }^{15} \mathrm{~N}$ a and ${ }^{13} \mathrm{C}$ levels $\mathbf{b}$ measured in control unlabelled sponges $\left(\delta^{15} \mathrm{~N}=0 \pm 30 \%\right.$ and $\delta^{13} \mathrm{C}=$ $0 \pm 35 \%$ o). The box-whisker plots display the data in quartiles, with the bottom of the box corresponding to the $25^{\text {th }}$ percentile, the line within the box marking the median and the top of the box corresponding to the $75^{\text {th }}$ percentile. The black lines outside the boxes connect the means of the time points to each other

pre-pulse samples and treated samples at $t=6 \mathrm{~h}$ (abbreviated hereafter as ' $t=0 \mathrm{~h}$ versus $t=6 \mathrm{~h}$ '), $P_{\text {(perm) }}<0.001$, Fig. 4a). During the chase over the next 3 days, dinoflagellates remained enriched at an enrichment level of 667 $\pm 224 \%$ o $\left(t=0 \mathrm{~h}\right.$ versus $\left.t=72 \mathrm{~h}, P_{\text {(perm) }}=0.012\right)$. The dinoflagellates hosted within $C$. orientalis cells are thus able to rapidly absorb and assimilate ammonium from the surrounding seawater, as known for coral dinoflagellates where ammonium is the preferred source of dissolved inorganic nitrogen [26, 35, 45, 51]. In the sponge, water movement through the canal network may allow for the rapid diffusion of ammonium to the intracellular dinoflagellates, possibly stimulated by photosynthetic energy during the pulse phase $[52,53]$. During photosynthesis, the profusion of energy and carbon compounds as acceptors for ammonium ions may facilitate direct incorporation of ammonium into amino acids potentially through the efficient yet energetically demanding GS/GOGAT pathway [25, 54, 55]. Intriguingly, the Symbiodinium-rich pinacoderm also directly takes up particulate organic nitrogen (shown in C. varians by [6]).

The carbon enrichment levels also differed between the treatment time points, but the response depended on the AOI in question (two-way interaction, Pseudo- $\mathrm{F}=5.052, P$ $($ perm $)=0.001)$. As expected, ${ }^{13} \mathrm{C}$-bicarbonate was taken up rapidly by the photosynthetic dinoflagellates, which displayed an organic enrichment of $2172 \pm 272 \%$ at $t=6 \mathrm{~h}$ (Fig. $4 \mathrm{~b}, t=0 \mathrm{~h}$ versus $\left.t=6 \mathrm{~h}, P_{(\text {perm })}<0.001\right)$. At the end of the chase $(t=72 \mathrm{~h})$, the enrichment had dropped significantly to $1055 \pm 116 \%$ o $(t=0 \mathrm{~h}$ versus $t=72 \mathrm{~h}$, as well as between $t=6 \mathrm{~h}$ and $t=72 \mathrm{~h}$, all $P_{(\text {perm })}<0.001$ ). At both time points, carbon enrichment was strongest in the dinoflagellates compared to the two other AOI (pairwise comparisons between the three AOI at $t=6 \mathrm{~h}$ and at $t=72 \mathrm{~h}$, all $P_{(\text {perm })}<0.01$ and $P_{(\text {perm })}<0.05$ respectively). The nitrogen and carbon enrichments found are comparable if not higher to enrichment previously found in clade C Symbiodinium of a symbiotic coral that was incubated in the same concentrations of the same sources [45], when the different incubation times are taken into account ( $48 \mathrm{~h}$ labelling pulse for the coral versus $6 \mathrm{~h}$ pulse in the current experiment).

The isotopic ratios of the cytoplasm of Symbiodiniumhosting cells revealed a less strong ${ }^{15} \mathrm{~N}$-enrichment at $t=6$ $\mathrm{h}(631 \pm 167 \%)\left(t=0 \mathrm{~h}\right.$ versus $t=6 \mathrm{~h}, P_{(\text {perm })}<0.001$, Fig. 4a), and showed high variability at $t=72 \mathrm{~h}(773 \pm$ $235 \%$ ) $\left(t=0 \mathrm{~h}\right.$ versus $\left.t=72 \mathrm{~h}, P_{\text {(perm) }}=0.012\right)$. Similarly, these cells were enriched in carbon, with enrichment ranging from $750 \pm 153 \%$ at $t=6 \mathrm{~h}$ to $653 \pm 65 \%$ at $t=72 \mathrm{~h}$ $\left(t=0 \mathrm{~h}\right.$ versus $t=6 \mathrm{~h}$ and $t=72 \mathrm{~h}$, both $P_{\text {(perm) }}<0.001$, Fig. $4 \mathrm{~b})$. At $t=72 \mathrm{~h}$, the ${ }^{13} \mathrm{C}$-enrichment level of the Symbiodinium-hosting cells was higher than that of mesohyl material (pairwise comparisons between the two AOI at $t=$ $\left.72 \mathrm{~h}, P_{(\text {perm })}=0.0028\right)$.

Mesohyl areas near Symbiodinium were scarcely enriched in nitrogen throughout the experiment, with at most $6 \%$ strongly enriched at $t=72 \mathrm{~h}(t=0 \mathrm{~h}$ versus $t=72 \mathrm{~h}, P$ $($ perm $)=0.012$, Fig. $3 \mathrm{~b}$ and $4 \mathrm{a})$. Mesohyl areas were more frequently enriched in carbon $(\sim 12 \%$ of the mesohyl AOI, Fig. 3b), with enrichment levels stable at $\sim 250 \pm 31 \%$ o $(t=$ $0 \mathrm{~h}$ versus $t=6 \mathrm{~h}$ and $t=72 \mathrm{~h}$, both $P_{\text {(perm) }}<0.001$, Fig. 4b). All enriched mesohyl material (both for nitrogen and carbon) was of host origin and no enriched prokaryotes were observed under the present experimental conditions, indicating that these sparse microorganisms most likely do not have an active role or at least have a lesser role in ammonium and bicarbonate assimilation in the outer layer of this sponge species.

Invertebrate hosts such as clams, jellyfish and sponges may infrequently digest their symbionts when under stress [54-58], yet here the dinoflagellate cell membranes and thylakoids of the examined cells appeared intact and 
without signs of digestion throughout the experiment. Given the lack of evidence of algal digestion, we argue that in the present case, the NanoSIMS quantification supports translocation of both nitrogen and carbon compounds incorporated by the dinoflagellates to the host cells that contain the dinoflagellates for a number of reasons: for nitrogen specifically, translocation is evident because only the hosting cells that contained enriched Symbiodinium were found to be enriched in nitrogen, and no other sponge cells took up ammonium during the pulse phase of the experiment. For carbon, since there are no pathways of direct inorganic carbon assimilation in animal cells, we suggest that bicarbonate was incorporated into photosynthates by Symbiodinium [59] and was then transported or leached out into the cytoplasm of the Symbiodinium-hosting cell. Already at $6 \mathrm{~h}$, one-third of Symbiodinium-hosting cells were enriched in nitrogen and almost twice as many were enriched in carbon (Fig. 3b, two-proportions test, $p=$ 0.027). At each time point, dinoflagellates enriched in nitrogen and/or carbon were in $\sim 70 \%$ of the cases hosted by enriched sponge cells, ie, translocation was a common phenomenon. Furthermore, Symbiodinium-hosting cells were never enriched unless they hosted an enriched dinoflagellate, which provides additional evidence for the autotrophic origin of the enrichment. The most parsimonious explanation for both tracers would be that translocation to the Symbiodinium-hosting cells already started during the $6 \mathrm{~h}$ pulse, rendering further translocation during the chase phase less pronounced.

In other symbiotic invertebrates such as Cnidaria and tridacnid clams, translocation of amino acids and photosynthates (principally glucose but also glycerol and organic acids) from Symbiodinium to non-Symbiodinium-hosting cells is well-established [60-62]. In the porous sponge body that is subject to constant water flow, it is more likely that enrichment signals may weaken over large surface areas away from the uptake site as compounds are processed by cellular metabolism and/or indirectly transferred to other cells through the mesohyl. However, the relatively low translocation we observed in non-Symbiodinium-hosting cells may also indicate that nitrogen or carbon-derived compounds are rapidly consumed to support basal metabolic rates, or are not used for host growth (and/or metabolism) in the outer sponge layer within the first $72 \mathrm{~h}$ after capture. Instead, the compounds may serve as a direct source to the amoeboid Symbiodinium-hosting cells: these cells have a high metabolic demand since they purportedly migrate vertically in the sponge body on a daily basis, transporting the symbiont to deeper layers at night to protect them from sponge predators and back to the surface by day for energy capture via photosynthetic activity [62]. It is unclear how the symbiont migration is controlled; potentially, all the symbiont energy is burnt in the migration and hence symbiont cells may have 'hijacked' host cells to improve their photosynthetic ability, without necessarily contributing to other energetically expensive activities of the host. Alternatively, this migration simultaneously serves for transportation of fixed materials to deeper layers of the host (eg, translocation of carbon to the choanosome as shown by [6]) not examined here.

The little nitrogen mesohyl enrichment that we found was only present during the chase phase (Fig. 4a), again implicating an indirect uptake of the enriched material through translocation. Symbiotic invertebrates are also able to directly assimilate ammonium (eg, shown by [35] under $20 \mu \mathrm{M}{ }^{15} \mathrm{NH}_{4} \mathrm{Cl}$ ), yet our results suggest that such a pathway was not generally active in the sponge under the experimental conditions. The ammonium concentration during the pulse $(5 \mu \mathrm{M})$ may have favoured GS/GOGAT pathways of Symbiodinium over GDH of the host; the latter pathway requires less energy yet higher ammonium loads due to lower ammonium affinity [64], which could imply a slower response time for direct assimilation by host cells. If the mechanism of ammonium assimilation is concentrationdependent [26], it would be of interest to determine whether a higher ammonium spike would lead to greater/faster activation of potential animal GDH. Under oligotrophic conditions, it appears that the dinoflagellates are chiefly responsible for incorporation of ammonium potentially into uric acid, urea or amino acids, as is the role of (prokaryotic) symbionts in other sponges [26, 28, 29, 31].

\section{Heterogeneity in ${ }^{15} \mathrm{~N}$ and ${ }^{13} \mathrm{C}$ enrichment}

The incorporation of ${ }^{15} \mathrm{~N}$ and ${ }^{13} \mathrm{C}$ was apparent in the majority of the dinoflagellates, yet some had incorporated one of the tracers only, or showed little incorporation of the tracers (Fig. 3b, Supplementary Table S4). This was particularly true for nitrogen, with enrichment in $59 \%$ of the Symbiodinium population measured after the $6 \mathrm{~h}$ pulse, as opposed to $93 \%$ of the population for carbon (two-proportions test, $p<0.0001, n=56$ cells). Although rates of carbon fixation by Symbiodiniumin hospite do not appear to depend on nitrogen availability [65], fixation products may differ; dinoflagellate cells enriched in carbon but not in nitrogen may imply production of sugars and lipids. We acknowledge that distinguishing between sugar/lipid and amino acid production (the latter being dependent on the nitrogen availability and therefore potentially stimulated by the provided pulse of ammonium) is beyond the scope of our study.

While part of the observed heterogeneity in isotopic enrichment could be linked to the orientation of the thin sectioning across specific subcellular structures of dinoflagellates [45], it is far too prevalent to be caused by sample bias or measurement noise only, especially since (i) 


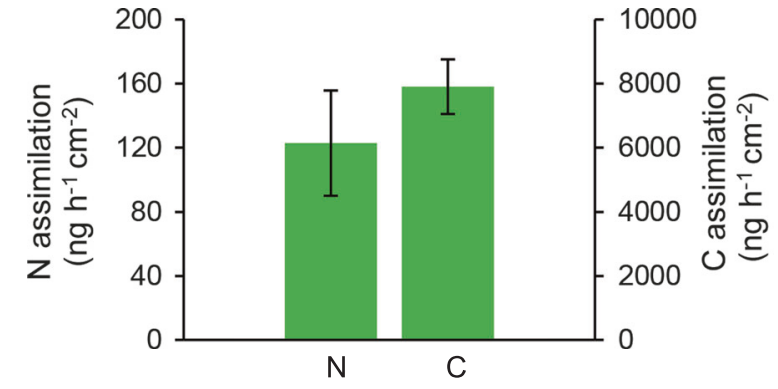

Fig. 5 Single-cell nitrogen and carbon assimilatory capacity of the dinoflagellate symbionts residing in the bioeroding sponge Cliona orientalis. Assimilation was quantified in $n=56$ Symbiodinium cells with NanoSIMS after a $6 \mathrm{~h}$ pulse of ${ }^{15} \mathrm{~N}$-ammonium- and ${ }^{13} \mathrm{C}$ bicarbonate-enriched seawater. Cellular uptake rates were normalized to the average $\mathrm{N}$ or $\mathrm{C}$ content of the symbiont cells and the pulse time according to the calculations provided by Dugdale and Wilkerson [80] and expressed per surface area of the sponge holobiont. Bars display mean \pm SEM

it was occasionally observed in the same field of view (eg, Fig. 2k, 1) and (ii) each NanoSIMS analysis included several layers and was therefore representative of a few tens of $\mathrm{nm}$ depth in the cellular material. Alternatively, variability could be caused by intercladal or interspecies metabolic heterogeneity [45], but only one species of Symbiodinium (S. endoclionum; [66]) belonging to clade $\mathrm{G}[67,68]$ has so far been described in $C$. orientalis. Within a lineage, variability in nutritional strategies may arise due to different microenvironments inside the sponge body, divergent life histories or cell cycle stages (eg, dissipation of enrichment signals upon cellular division), or stochastic gene expression of cellular transporters or assimilation pathways among cells [69]. Ultimately, the cell-to-cell metabolic heterogeneity found within the Symbiodinium population (undetectable in bulk studies but revealed with NanoSIMS) may have important implications for stability and competitive advantage inside the host microenvironment, as shown for a number of microorganisms [70].

The NanoSIMS technique furthermore revealed spatial heterogeneity in ${ }^{15} \mathrm{~N}$ and ${ }^{13} \mathrm{C}$ enrichment within single Symbiodinium cells, in addition to that observed between cells. Subcellular enrichment hotspots are commonly observed in NanoSIMS analyses and they contribute to the large SDs produced for each per cell measured (eg, [35, 45]). Similarly to coral dinoflagellates, this heterogeneity may reflect temporary storage of nitrogen in cytosolic crystalline structures [26] and carbon in intracellular lipid droplets and starch granules of the chloroplast pyrenoid or the cytosol [71].

\section{Symbiodinium-specific ${ }^{15} \mathrm{~N}$-ammonium and ${ }^{13} \mathrm{C}$ - bicarbonate uptake rates}

During the $6 \mathrm{~h}$ pulse, Symbiodinium fixed nitrogen and carbon at specific uptake rates of $122 \pm 32 \mathrm{ng} \mathrm{N} \mathrm{h}^{-1} \mathrm{~cm}^{-2}$ and $7901 \pm 853 \mathrm{ng} \mathrm{Ch}^{-1} \mathrm{~cm}^{-2}$, respectively (Fig. 5). Variability in the duration and concentration of the labelling pulse makes it difficult to compare to existing NanoSIMS uptake rates, but our results fall in the same order of magnitude as previously reported for Symbiodinium in coral $\left(504 \pm 28 \mathrm{ng} \mathrm{N} \mathrm{h}^{-1} \mathrm{mg}^{-1}\right.$ (standardized to mass of dinoflagellates), which is equivalent to $385 \pm 21 \mathrm{ng} \mathrm{N} \mathrm{h}^{-1} \mathrm{~cm}^{-2}$; [35]) and for a free living dinoflagellate $\left(\sim 2 \mathrm{pg} \mathrm{Ch}^{-1}\right.$ per cell that would be equivalent to $2816 \mathrm{ng} \mathrm{Ch}^{-1} \mathrm{~cm}^{-2}$ in the sponge; [69]). Despite rapid osmium post-fixation before rinsing and while avoiding acetone storage of the samples, low-molecular weight compounds that are soluble and poor in amino-groups may not always be successfully immobilized during the fixation protocol used in this study. Therefore, absolute uptake rates especially of bicarbonate represent mostly incorporation into macromolecules and may be an underestimate of the total uptake of the tracer.

\section{Ecological significance}

Stimulation of bioerosion by light has been suggested for a number of photosymbiotic bioeroding species [3-5], including $C$. orientalis [14]. Accordingly, the bioerosion rates of $C$. orientalis decrease after prolonged bleaching due to heat stress [72] or after artificial inhibition of photosynthesis (Achlatis et al., unpublished data). Our NanoSIMS results provide evidence of strong fixation of carbon and nitrogen by Symbiodinium in the light and transfer of carbon and nitrogen compounds at least to specific cell types, but we did not examine potential translocation of these nutrients to the etching cells in deeper sponge layers. Although direct or indirect stimulation of bioerosion by Symbiodinium-harvested energy is most likely, we cannot exclude the potential that (auto)trophic bacteria deeper in the sponge (also) supply energy for etching. Future studies may clarify the abundance and function of prokaryotic symbionts or migrating Symbiodinium with regard to (chemo)autotrophic or non-photosynthetically-driven assimilation of nitrogen and carbon.

While calcifying corals are in decline worldwide [73, 74], the prevalence and excavating activity of photosymbiotic bioeroding sponges has been observed to increase on disturbed reefs $[75,76]$. The upper thermal limit of the partnership between Symbiodinium and bioeroding sponges is considered higher than that of the respective scleractinian symbiosis, possibly enabling bioerosion to temporarily persist as global warming impairs rates of calcification [7, 77]. Understanding the metabolic interaction between bioeroding sponges and their symbiotic dinoflagellates will enhance projections of the response of bioeroding sponges and their excavating activity to warming, acidification and eutrophication of reef environments. This provides valuable 
insight into the competition dynamics between calcifying corals and decalcifying sponges, with important implications for the carbonate budgets of coral reefs.

\section{Conclusion}

We have provided imaging and quantification of nitrogen and carbon assimilation at the single-cell level in the bioeroding sponge $C$. orientalis, using NanoSIMS analysis in combination with TEM ultrastructural observations. In a novel application of NanoSIMS to (bioeroding) sponges, we provide a qualitative and quantitative baseline of the metabolic integration and translocation of nutrients within the outer layer of a sponge holobiont. In this regard, NanoSIMS is a powerful tool that bridges the functional potential of symbiotic partners to experimental evidence of realized metabolic pathways. The metabolism of carboncontaining photosynthates is well established in other symbiotic invertebrates and the fate of nitrogen-containing compounds is also being explored [78]; for both these pathways, we provide a reference description inside a less studied symbiosis. Our data show clear differences in the roles of the host and microbial cells, stressing the precedence of the dinoflagellate symbiont over prokaryotic symbionts in the outer layers of $C$. orientalis for the efficient uptake of inorganic nutrients in oligotrophic reef waters. All in all, our results provide new insights into how light-dependent symbioses in sponges enable both hosts and symbionts to function in microhabitats that would otherwise be unfavourable.

Acknowledgements We thank R. van der Zande for assistance during set-up and sampling of the pulse-chase experiment. We also thank C. H. L. Schönberg, D. Bender-Champ, A. Kubicek, K. Brown as well as the Heron Island Research staff for advice and/or assistance in the field. All research was conducted under permit no. G14/37212.1 (GBR Marine Park Authority). We are grateful to the anonymous reviewers of the manuscript for their valuable suggestions.

Funding Financial support by the Australian Research Council Laureate grant FL120100066 (to O. H.-G.), the ARC Centre of Excellence for Coral Reef Studies CE0561435 (to S. D. and O. H.-G.), the Australian Government Research Training Program Scholarship and the Holsworth Wildlife Research Endowment by the Ecological Society of Australia (to M. A.) is gratefully acknowledged. The Australian Microscopy and Microanalysis Research Facility, the Science and Industry Endowment Fund, and the State Government of Western Australian are kindly acknowledged for contributing to the Ion Probe Facility at the University of Western Australia.

\section{Compliance with ethical standards}

Conflict of interest The authors declare that they have no conflict of interest.

\section{References}

1. Gattuso J, Allemand D, Frankignoulle M. Photosynthesis and calcification at cellular, organismal and community levels in coral reefs: a review on interactions and control by carbonate chemistry. Am Zool. 1999;39:160-83.

2. Muscatine L. The role of symbiotic algae in carbon and energy flux in reef corals. Ecosyst World. 1990;25:75-87.

3. Hill MS. Symbiotic Zooxanthellae enhance boring and growth rates of the tropical sponge Anthosigmella varians forma varians. Mar Biol. 1996;125:649-54.

4. Rosell D, Uriz MJ. Do associated Zooxanthellae and the nature of the substratum affect survival, attachment and growth of Cliona viridis (Porifera: Hadromerida)? An experimental approach. Mar Biol. 1992;114:503-7.

5. Schönberg CHL. Growth and erosion of the zooxanthellate Australian bioeroding sponge Cliona orientalis are enhanced in light. Proc 10th Int Coral Reef Symp Okinawa. 2006;1:168-74.

6. Weisz JB, Massaro AJ, Ramsby BD, Hill MS. Zooxanthellar symbionts shape host sponge trophic status through translocation of carbon. Biol Bull. 2010;219:189-97.

7. Schönberg CHL, Fang JKH, Carballo JL. Bioeroding sponges and the future of coral reefs. Climate change, ocean acidification, and sponges. Berlin/Heidelberg: Springer; 2017. p. 179-372.

8. Pomponi SA. Cytological mechanisms of calcium carbonate excavation by boring sponges. Int Rev Cytol. 1980;65:301-19.

9. Zundelevich A, Lazar B, Ilan M. Chemical versus mechanical bioerosion of coral reefs by boring sponges-lessons from Pione $c f$. vastifica. J Exp Biol. 2007;210:91-6.

10. Glynn PW. Bioerosion and coral-reef growth: a dynamic balance. Life and death of coral reefs. New York: Chapmann and Hall; 1997. p. 68-95.

11. Schönberg CHL. Bioeroding sponges common to the Central Australian Great Barrier Reef: descriptions of three new species, two new records, and additions to two previously described species. Senck Marit. 2000;30:161-221.

12. Vacelet J. Algal-sponge symbioses in the coral reefs of New Caledonia: a morphological study. Proc 4th Int Coral Reef Symp Manila. 1981;2:713-9.

13. Rützler K. (1990) Associations between Caribbean sponges and photosynthetic organisms. In: Rützler K (ed). New Perspectives in Sponge Biology. Smithsonian Institution Press, Washington, DC, pp 455-466.

14. Fang JKH, Schönberg CHL, Hoegh-Guldberg O, Dove S. Daynight ecophysiology of the photosymbiotic bioeroding sponge Cliona orientalis Thiele, 1900. Mar Biol. 2016;163:1-12.

15. Gloeckner V, Wehrl M, Moitinho-Silva L, Gernert C, Schupp P, Pawlik JR, et al. The HMA-LMA dichotomy revisited: an electron microscopical survey of 56 sponge species. Biol Bull. 2014;227:78-88.

16. Poppell E, Weisz J, Spicer L, Massaro A, Hill A, Hill MS. Sponge heterotrophic capacity and bacterial community structure in high-and low-microbial abundance sponges. Mar Ecol. 2014;35:414-24.

17. Hentschel U, Usher KM, Taylor MW. Marine sponges as microbial fermenters. FEMS Microbiol Ecol. 2006;55:167-77.

18. Thomas T, Moitinho-Silva L, Lurgi M, Björk JR, Easson C, Astudillo-García C, et al. Diversity, structure and convergent evolution of the global sponge microbiome. Nat Commun. 2016;7:11870

19. Usher KM. The ecology and phylogeny of cyanobacterial symbionts in sponges. Mar Ecol. 2008;29:178-92.

20. Wilkinson C. Nutrient translocation from symbiotic cyanobacteria to coral reef sponges. Biologie des spongiaires. Paris: Colloques 
International du Centre National de la Recherche Scientifique; 1979. Vol. 291. p. 373-80.

21. Freeman CJ, Thacker RW, Baker DM, Fogel ML. Quality or quantity: is nutrient transfer driven more by symbiont identity and productivity than by symbiont abundance? ISME J. 2013;7:1116-25.

22. López-Legentil S, Song B, McMurray SE, Pawlik JR. Bleaching and stress in coral reef ecosystems: $h s p 70$ expression by the giant barrel sponge Xestospongia muta. Mol Ecol. 2008;17:1840-9.

23. Thacker RW. Impacts of shading on sponge-cyanobacteria symbioses: a comparison between host-specific and generalist associations. Integr Comp Biol. 2005;45:369-76.

24. D'Elia CF, Domotor SL, Webb KL. Nutrient uptake kinetics of freshly isolated Zooxanthellae. Mar Biol. 1983;75:157-67.

25. Rahav O, Dubinsky Z, Archituv Y, Falkowski PG. Ammonium metabolism in the zooxanthellate coral, Stylophora pistillata. Proc R Soc Lond B. 1989;337:325-37.

26. Kopp C, Pernice M, Domart-Coulon I, Djediat C, Spangenberg JE, Alexander DTL, et al. Highly dynamic cellular-level response of symbiotic coral to a sudden increase in environmental nitrogen. MBio. 2013;4:e00052-13.

27. Fan L, Reynolds D, Liu M, Stark M, Kjelleberg S, Webster NS, et al. Functional equivalence and evolutionary convergence in complex communities of microbial sponge symbionts. Proc Natl Acad Sci USA. 2012;109:E1878-87.

28. Fiore CL, Jarett JK, Olson ND, Lesser MP. Nitrogen fixation and nitrogen transformations in marine symbioses. Trends Microbiol. 2010;18:455-63.

29. Fiore CL, Labrie M, Jarett JK, Lesser MP. Transcriptional activity of the giant barrel sponge, Xestospongia muta holobiont: molecular evidence for metabolic interchange. Front Microbiol. 2015;6:364

30. Hentschel U, Piel J, Degnan SM, Taylor MW. Genomic insights into the marine sponge microbiome. Nat Rev Microbiol. 2012;10:641-54.

31. Moitinho-Silva L, Díez-Vives C, Batani G, Esteves AI, Jahn MT, Thomas T. Integrated metabolism in sponge-microbe symbiosis revealed by genome-centered metatranscriptomics. ISME J. 2017;11:1651-66.

32. Hansen AK, Moran NA. Aphid genome expression reveals hostsymbiont cooperation in the production of amino acids. Proc Natl Acad Sci USA. 2011;108:2849-54.

33. Lee R, Robinson J, Cavanaugh C. Pathways of inorganic nitrogen assimilation in chemoautotrophic bacteria-marine invertebrate symbioses: expression of host and symbiont glutamine synthetase. J Exp Biol. 1999;202:289-300.

34. Bender DA. Amino acid metabolism. New York: Wiley Interscience; 1985.

35. Pernice M, Meibom A, Van Den Heuvel A, Kopp C, DomartCoulon I, Hoegh-Guldberg O, et al. A single-cell view of ammonium assimilation in coral-dinoflagellate symbiosis. ISME J. 2012;6:1314-24.

36. Srivastava M, Simakov O, Chapman J, Fahey B, Gauthier ME, Mitros T, et al. The Amphimedon queenslandica genome and the evolution of animal complexity. Nature. 2010;466:720-6.

37. Riesgo A, Peterson K, Richardson C, Heist T, Strehlow B, McCauley M, et al. Transcriptomic analysis of differential host gene expression upon uptake of symbionts: a case study with Symbiodinium and the major bioeroding sponge Cliona varians. BMC Genomics. 2014;15:376.

38. King N, Westbrook MJ, Young SL, Kuo A, Abedin M, Chapman $\mathrm{J}$, et al. The genome of the choanoflagellate Monosiga brevicollis and the origin of metazoans. Nature. 2008;451:783-8.

39. Musat N, Foster R, Vagner T, Adam B, Kuypers MM. Detecting metabolic activities in single cells, with emphasis on nanoSIMS. FEMS Microbiol Rev. 2012;36:486-511.
40. Pernice M, Levy O. Novel tools integrating metabolic and gene function to study the impact of the environment on coral symbiosis. Front Microbiol. 2014;5:448.

41. Schönberg CHL, Fang JKH, Carreiro-Silva M, Tribollet A, Wisshak M. Bioerosion: the other ocean acidification problem. ICES J Mar Sci. 2017;74:895-925.

42. Sampayo EM, Ridgway T, Franceschinis L, Roff G, HoeghGuldberg O, Dove S. Coral symbioses under prolonged environmental change: living near tolerance range limits. Scientific reports. 2016;6:36271.

43. Staunton Smith J, Johnson CR. Nutrient inputs from seabirds and humans on a populated coral cay. Mar Ecol Prog Ser. 1995;10:189-200.

44. Meyer JL, Schultz ET. Migrating haemulid fishes as a source of nutrients and organic matter on coral reefs. Limnol Oceanogr. 1985;30:146-56.

45. Pernice M, Dunn SR, Tonk L, Dove S, Domart-Coulon I, Hoppe $\mathrm{P}$, et al. A nanosims study of dinoflagellate functional diversity in reef-building corals. Environ Microbiol. 2014;17:3570-80.

46. Wangpraseurt D, Pernice M, Guagliardo P, Kilburn MR, Clode PL, Polerecky L, et al. Light microenvironment and single-cell gradients of carbon fixation in tissues of symbiont-bearing corals. ISME J. 2015;10:788-92.

47. Clarke KR, Gorley RN. PRIMERv6: user manual/tutorial. Plymouth: PRIMER-E Ltd; 2006.

48. Anderson MJ, Gorley RN, Clarke KR. PERMANOVA+ for PRIMER: guide to software and statistical methods. Plymouth: PRIMER-E Ltd; 2008.

49. Gao D, Huang X, Tao Y. A critical review of NanoSIMS in analysis of microbial metabolic activities at single-cell level. Crit Rev Biotechnol. 2016;36:884-90.

50. Fleiss JL, Levin B, Paik MC. Statistical methods for rates and proportions. New Jersey: Wiley; 2003.

51. Grover R, Maguer JF, Allemand D, Ferrier-Pages C. Uptake of dissolved free amino acids by the scleractinian coral Stylophora pistillata. J Exp Biol. 2008;211:860-65.

52. Leys SP, Yahel G, Reidenbach MA, Tunnicliffe V, Shavit U, Reiswig HM. The sponge pump: the role of current induced flow in the design of the sponge body plan. PLoS ONE. 2011;6:e27787.

53. Strehlow BW, Jorgensen D, Webster NS, Pineda MC, Duckworth A. Using a thermistor flowmeter with attached video camera for monitoring sponge excurrent speed and oscular behaviour. PeerJ. 2016; 4:e2761

54. Foyer $\mathrm{CH}$, Parry M, Noctor G. Markers and signals associated with nitrogen assimilation in higher plants. J Exp Bot. 2003;54:585-93.

55. Muscatine L, D'Elia C. The uptake, retention, and release of ammonium by reef corals. Limnol Oceanogr. 1978;23:725-34.

56. Hill MS, Hill A. The magnesium inhibition and arrested phagosome hypotheses: new perspectives on the evolution and ecology of Symbiodinium symbioses. Biol Rev. 2012;87:804-21.

57. Rosell D. Effects of reproduction in Cliona viridis (Hadromerida) on Zooxanthellae. Sci Mar. 1993;57:405-13.

58. Strehlow B, Friday S, McCauley M, Hill MS. The potential of azooxanthellate poriferan hosts to assess the fundamental and realized Symbiodinium niche: evaluating a novel method to initiate Symbiodinium associations. Coral Reefs. 2016;35:1201-12.

59. Trench R. Microalgal-invertebrate symbioses-a review. Endocyto Cell Res. 1993;9:135-75.

60. Burriesci MS, Raab TK, Pringle JR. Evidence that glucose is the major transferred metabolite in dinoflagellate-cnidarian symbiosis. J Exp Biol. 2012;215:3467-77.

61. Wang J-T, Douglas AE. Nitrogen recycling or nitrogen conservation in an alga-invertebrate symbiosis? J Exp Biol. 1998;201:2445-53. 
62. Yellowlees D, Rees TAV, Leggat W. Metabolic interactions between algal symbionts and invertebrate hosts. Plant Cell Environ. 2008;31:679-94.

63. Schönberg CHL, Suwa R. Why bioeroding sponges may be better hosts for symbiotic dinoflagellates than many corals. In: Porifera research: biodiversity, innovation and sustainability. Rio de Janeiro: National Museum; 2007. p. 569-80.

64. Harper C, Hayward D, Wiid I, van Helden P. Regulation of nitrogen metabolism in Mycobacterium tuberculosis: a comparison with mechanisms in Corynebacterium glutamicum and Streptomyces. IUBMB Life. 2008;60:643-50.

65. Falkowski PG, Dubinsky Z, Muscatine L, McCloskey L. Population control in symbiotic corals. Bioscience. 1993;43:606-11.

66. Ramsby BD, Hill MS, Thornhill DJ, Steenhuizen SF, Achlatis M, Lewis AM, et al. Sibling species of mutualistic Symbiodinium clade $\mathrm{G}$ from bioeroding sponges in the western Pacific and western Atlantic oceans. J Phycol. 2017;53:951-60.

67. Hill MS, Allenby A, Ramsby B, Schönberg C, Hill A. Symbiodinium diversity among host clionaid sponges from Caribbean and Pacific reefs: evidence of heteroplasmy and putative host-specific symbiont lineages. Mol Phylogenet Evol. 2011;59:81-8.

68. Schönberg CHL, Loh WKW. Molecular identity of the unique symbiotic dinoflagellates found in the bioeroding demosponge Cliona orientalis. Mar Ecol Prog Ser. 2005;299:157-66.

69. Matantseva O, Skarlato S, Vogts A, Pozdnyakov I, Liskow I, Schubert H, et al. Superposition of individual activities: ureamediated suppression of nitrate uptake in the dinoflagellate Prorocentrum minimum revealed at the population and single-cell levels. Front Microbiol. 2016;7:1310.

70. Kaern M, Elston TC, Blake WJ, Collins JJ. Stochasticity in gene expression: from theories to phenotypes. Nat Rev Genet. 2005;6:451-64.
71. Kopp C, Domart-Coulon I, Escrig S, Humbel BM, Hignette M, Meibom A. Subcellular investigation of photosynthesis-driven carbon and nitrogen assimilation and utilization in the symbiotic reef coral Pocillopora damicornis. MBio. 2015;6:e02299-14.

72. Achlatis M, van der Zande RM, Schönberg CHL, Fang JKH, Hoegh-Guldberg O, Dove S. Sponge bioerosion on changing reefs: ocean warming poses physiological constraints to the success of a photosymbiotic excavating sponge. Sci Rep. 2017;7:10705.

73. Hughes TP, Kerry J, Álvarez-Noriega M, Álvarez-Romero J, Anderson K, Baird A, et al. Global warming and recurrent mass bleaching of corals. Nature. 2017;543:373-7.

74. De'ath G, Lough JM, Fabricius KE. Declining coral calcification on the Great Barrier Reef. Science. 2009;323:116-9.

75. Rützler K. Impact of crustose clionid sponges on Caribbean reef corals. Acta Geol Hisp. 2002;37:61-72.

76. Schönberg CHL, Ortiz JC. Is sponge bioerosion increasing? Proc 11th Int Coral Reef Symp Ft Lauderdale. 2008;1:527-30.

77. Fang JKH, Mello-Athayde MA, Schönberg CHL, Kline DI, Hoegh-Guldberg O, Dove S. et al. Sponge biomass and bioerosion rates increase under ocean warming and acidification. Glob Chang Biol. 2013;19:3581-91.

78. Rädecker N, Pogoreutz C, Voolstra CR, Wiedenmann J, Wild C. Nitrogen cycling in corals: the key to understanding holobiont functioning? Trends Microbiol. 2015;23:490-7.

79. Pineda M-C, Strehlow B, Duckworth A, Doyle J, Jones R, Webster NS. Effects of light attenuation on the sponge holobiontimplications for dredging management. Sci Rep. 2016;6:39038.

80. Dugdale R, Wilkerson F. The use of ${ }^{15} \mathrm{~N}$ to measure nitrogen uptake in eutrophic oceans: experimental considerations. Limnol Oceanogr. 1986;31:673-89. 